\title{
Hindsight bias in a very sparse environment
}

\author{
JUDITH E. HENNESSEY \\ California State University, Northridge, California \\ and \\ STEPHEN E. EDGELL \\ University of Louisville, Louisville, Kentucky
}

\begin{abstract}
Hindsight bias, the inability to ignore outcome information, was studied in a sparse and abstract environment, that of a probability learning task. Following the probability learning task, the subjects were asked to estimate the probability of the events. The subjects in the hindsight conditions were provided outcome information. They were unable to ignore the outcome information even though they were instructed to do so. Their mean probability estimates deviated in the direction of the outcome information they received. This was found for subjects who received the "actual probabilities" as outcome information as well as for subjects who were only given what the event on the next trial would have been.
\end{abstract}

Hindsight bias occurs when a person's estimate of the likelihood of a possible outcome is influenced by knowledge of what outcome actually has occurred even though the person is attempting to ignore this knowledge. Examples of this are numerous. Decisions are often strongly criticized after the fact when the outcome of the decision is found to be undesirable. It is well known that it is difficult for one not to see the decision as obviously being in error after the fact. This is true even though one may well have agreed with the decision before the fact. Common folk wisdom says that hindsight is $20 / 20$. Fischhoff (1982) reported that hindsight bias was a robust and widespread phenomenon.

Fischhoff (1975) defined the standard for experiments on hindsight bias. Subjects were given passages to read about historical events. They were then given the "actual" outcome and asked to judge the likelihood of several possible outcomes. Any given outcome was judged more likely when it was presented as the outcome that actually did occur than when one of the other possible outcomes was presented as the one that actually occurred. Fischhoff and Beyth (1975) extended these results outside the laboratory in a real-life setting with subjects who made judgments before and after real-world events (President Nixon's trips to Peking and Moscow). Slovic and Fischhoff (1977) extended the findings from historical scenarios to scientific experiment scenarios.

Fischhoff (1977) extended the findings to the answering of questions about facts. When the hindsight bias effect was explained to subjects and they were asked to try to avoid it, their hindsight bias was not diminished. Wood (1978) ran a similar study, in which he introduced a time delay and reduced the demand characteristics of the task by disguising it as a study of general student knowledge.

Correspondence should be addressed to Stephen E. Edgell, Department of Psychology, University of Louisville, Louisville, KY 40292.
However, hindsight bias was still found across all the conditions. Hasher, Attig, and Alba (1981), following the same paradigm, told subjects that they had erred in giving the correct answers and that they had given the wrong answers. The subjects simply reversed the bias in favor of the inferred correct answer. When they were told that some of the answers were wrong-but not which onesthere was less hindsight bias.

Arkes, Faust, Guilmette, and Hart (1988) more recently found less hindsight bias in the clinical diagnosis of neuropsychologists when they were not asked to give reasons for the diagnosis provided. Reverse hindsight bias has been reported in two recent studies. Verplanken and Pieters (1988) found a reverse hindsight bias for the Chernobyl nuclear accident of 1986 , the strength of which was moderated by "need for cognition." Subjects evaluating computer software quality showed a reverse hindsight bias in their recall of expectations for surprising events (Mazursky \& Ofir, 1990). From this recent work, it is clear that for events that are believed to be highly unlikely, outcome bias may be in a different direction.

Goitein and Rotenberg (1977) extended the finding of hindsight bias to a task of predicting the status of a person from a personality description. Bukszar and Connolly (1988), hypothesizing that more expert judges would not show the hindsight bias, used advanced students in an MBA program judging return on companies' investments, but still found the usual hindsight bias. Detmer, Fryback, and Gassner (1978) went a step further and tried surgeons in a medical task, but still found hindsight bias. Arkes, Wortmann, Saville, and Harkness (1981) had the same results with physicians. Two other attempts to eliminate hindsight biases were partially successful. Davies (1987) found some lessening of the hindsight bias by having subjects review thoughts that they had recorded while reading the narrative before receiving the outcome information. However, Davies found that this method did not 
lower the hindsight bias as much as the Slovic and Fischhoff (1977) method of generating alternative explanations did. Pennington (1981) found little or no hindsight bias in a real-world task (a British firemen's strike) if the subjects generated their own outcomes, but found the usual hindsight bias if possible outcomes were given to the subjects.

In several studies, researchers have looked at possible social factors that might influence hindsight bias. Leary (1981), in studying a real-world event (a football game), found no effect of either the level of self-esteem (public or private predictions) or the level of involvement (level of knowledge of the game) on the amount of hindsight bias; the usual hindsight bias was found. Synodinos (1986) found identical results with respect to another real-world event (the governor's race in Hawaii), which was replicated for the 1980 presidential election by Leary (1982) and for the 1984 presidential election by Powell (1988). Campbell and Tesser (1983), using a task like Wood's (1978) rather than a real-world task, found a correlation between the amount of hindsight bias that subjects showed and both their need to be able to predict and their selfpresentation motive.

Hawkins and Hastie (1990) offered four strategies for responding to hindsight questions, and from their review of empirical research, they concluded that a reevaluation of case-specific evidence is the most common underlying explanation of hindsight bias. This explanation was supported by Carli and Leonard (1989), who controlled hindsight bias by providing a positive outcome (a promotion) or a negative outcome (rape) to identical scenarios involving a woman. The evaluation of character information was positive for the promotion outcome and more negative for the rape outcome. An earlier study in which the rape outcome and a neutral outcome, rather than a positive outcome, yielded victim blaming for the rape outcome, although the nature of the blaming was behavioral rather than character-based (Janoff-Bulman, Timko, \& Carli, 1985). Goggin and Range (1985) found hindsight bias after an outcome of suicide. The results consisted of observers' more negative view of the deceased person's family.

Hindsight bias also has serious implications in many applied judgment areas. For example, hindsight bias would predict that juries would not be able to ignore information that they have received but have been instructed to ignore. Indeed, in two instances, studies have yielded exactly that (Casper, Benedict, \& Kelly, 1988; Sue, Smith, \& Caldwell, 1973). Wexler and Schopp (1989) reviewed various ways in which hindsight bias might be reduced in juries, including the use of an expert witness testifying on the hindsight bias itself.

All of the experiments discussed above have involved complex environments. The situations or scenarios provided the subject with many complex dimensions of information, the interpretation of which was uncertain and complex. The outcomes were complex, and the possible outcomes were usually many. The relationships between the information and the outcomes were always unknown.
The subjects had to generate relationships from their knowledge. It was of interest to see whether the hindsight bias was so robust that it would be found in a much simpler environment, one without the complexities and the unknown correct interpretations and relationships of the environments used before. The simplest possible decisionmaking environment has only two possible outcomes. Making these outcomes abstract further reduces any interpretation bias that a subject might have. The simplest way to give information about the likelihood of the two possible outcomes is to do so through direct exposure to a sequence of such outcomes-that is, to give the subject many trials in which one of the two possible outcomes occurs on each trial (i.e., a probability learning task). Vlek (1970) showed that subjects in a probability learning task, when asked to estimate the relative frequency of an event's occurrence, give estimates that accurately reflect their asymptotic response levels. It is well known that these asymtotic response levels match the actual event probability for moderate event probabilities.

Following the probability learning task, the subject would have sufficient information to judge the likelihood of the two possible outcomes. Following the general form of hindsight experiments, the subjects could be given the "actual" probabilities as outcome information. They would then be requested to ignore this information and respond as they would have done before receiving it. An even weaker manipulation would be to ask the subjects to judge the probability of each outcome's occurring on the next trial and to provide them with the "actual" outcome that would have occurred. Five groups of subjects were run. All subjects participated in a binary probability learning task. One group (the foresight group) did not receive any outcome information. Half of the remaining subjects were given probability information, and the other half were given the outcome that would have occurred on the next trial. One half of the subjects in each group were biased in one direction, and the other half were biased in the other direction. For the probability information groups, one group (biased high) was given a higher probability $(.8)$ than the correct value $(.7)$ for the more likely outcome, and the other group (biased low) was given a value lower (.6). For the outcome groups, one group (biased high) was given the more likely outcome, and the other group (biased low) was given the less likely outcome.

\section{METHOD}

\section{Subjects}

The subjects were 78 students who were satisfying a course requirement in introductory psychology.

\section{Apparatus}

The apparatus for the probability learning task consisted of four CRT screens and keyboards. Two response keys were marked on the keyboards with colored tape (red or green). Stimulus presentation and response collection were controlled by a computer.

\section{Procedure}

The subjects were randomly assigned to one of the five experimental groups, with a total of 15 or 16 subjects in each group. Each subject 
was given 120 trials of a binary probability learning task with trials randomly permuted in blocks of 20 . Work in probability learning has demonstrated that by the time subjects have completed 100 trials, they are performing at asymptotic levels (Estes, 1959; Luce \& Suppes, 1965). Outcomes for all groups were presented as either the word RED or the word GREEN on a CRT screen. The outcome GREEN occurred $70 \%$ of the time. The outcome RED occurred $30 \%$ of the time. An X appeared on the screen to mark the beginning of a trial. On each trial, the subjects were asked to predict which of the two possible outcomes would occur on that trial by pressing one of two buttons (red or green) corresponding to the predictions. The subjects were then presented with the outcome that actually occurred.

Upon completion of the probability learning task, the subjects completed a questionnaire calling for their subjective probability judgments. Until this time, however, the subjects were not led to believe that they would later be called upon to make such subjective probability judgments. The subjects in the foresight group were then asked, in view of the information obtained in the preceding task, the probability that the outcome of the next trial would be the outcome GREEN, should the task continue for another trial. They were also asked the probability that the outcome would be RED. The subjects in the hindsight groups were first given outcome information depending on the experimental group to which they were assigned as described above, and then they were asked to ignore this information before responding to the same questions. All subjects were told that their judgments should sum to 100 . (Percentages were used with the subjects rather than probabilities, because subjects are usually more familiar with percentages.)

\section{RESULTS AND DISCUSSION}

Two measures were obtained from each subject-the proportion of GREEN responses over the last 20 trials of the probability learning task, and the subjective probability estimate of the more frequent outcome. Means across subjects within groups were calculated for this second measure. Figure 1 shows these means plotted as a function of bias direction and type; the mean for the foresight group is plotted across the graph for purposes of comparison.

As can be seen in Figure 1, the mean subjective probability estimate of the event GREEN by the foresight group

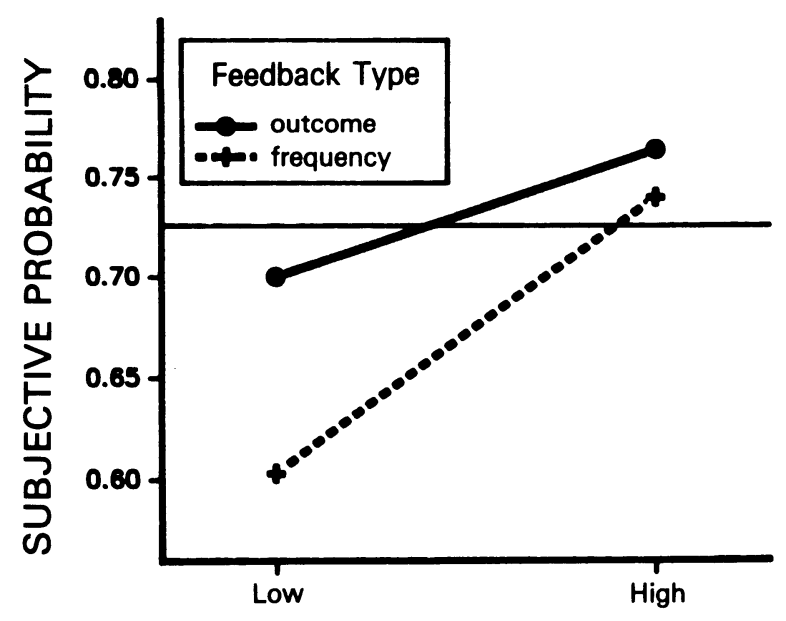

BIAS DIRECTION

Figure 1. Mean subjective probability judgments for the more frequent outcome, as a function of experimental group. Although the foresight group did not receive any outcome information, its mean is given by a horizontal line for purposes of comparison. was very close to the actual value of .7 , and it was not significantly different $[t(15)=.20, p=.84]$. This was expected, and it verifies that the probability learning task gave the subjects the desired information.

In an effort to control for the variability in subjects' asymptotic response proportions, response proportions obtained for the GREEN response on the last 20 trials of the probability learning task were used as a covariate in the analysis of the subjective probability estimates for the outcome GREEN. A $2 \times 2$ analysis of covariance on the four hindsight groups revealed a significant main effect for biasing direction $[F(1,57)=7.97, p<.01]$. As can be seen in Figure 1, subjects biased low assigned significantly lower probabilities to the outcome GREEN than did subjects biased high. The effect for the type of outcome provided to the subject (actual event or biased relative frequency) approached significance $[F(1,57)=3.55$, $p<.10$ ]. As can be seen in Figure 1, there appears to have been a tendency for the groups given relative frequency information to give lower mean subjective probabilities to the outcome GREEN than those given by the groups that received outcome information. The interaction and the effect of the covariate were not significant $[F(1,57)=1.27, p=.26$, and $F(1,57)=.84, p=.36$, respectively].

In the relative-frequency hindsight groups, it was possible that subjects were submitting directly to the authority of the experimenter by echoing the relative frequencies they were given. However, subjects given relativefrequency outcome knowledge responded with a subjective probability estimate that was the same as the relative frequency given them only $17 \%$ of the time. These same subjective probability values appeared in the two "actual" outcome knowledge groups $19 \%$ of the time. This finding precludes such an explanation.

Figure 1 reveals that the hindsight bias was found for both types of outcome feedback (relative frequency and next trial outcome). For the groups receiving relativefrequency feedback, the effect appears to have been larger for the group anchored low than for the group anchored high. This is consistent with the general findings in hindsight bias research. It can easily be explained by a ceiling effect. That is, one's judgment cannot change as much in the direction of zero (for the less likely outcome) or one (for the more likely outcome) as it can in the other direction, because of these limits of zero and one. The amount of bias for the groups given the outcome on the next trial appears to have been about equal for the group anchored low and the group anchored high.

Indeed, hindsight bias is a robust effect. The environment in the present experiment could not have been simpler, yet hindsight bias was found. Even when the feedback consisted just of the results of the next trial, hindsight bias was found. There may well be no way to counter hindsight bias. In some previous studies, less hindsight bias was found when the subject concentrated on information that would tend to balance the judgment away from the hindsight bias direction. However, in actual decisionmaking situations, it may be difficult or impossible to im- 
plement these tactics. Since hindsight bias can be so destructive to good judgment and is so prevalent, it is imperative that decision makers be educated about the existence of hindsight bias.

\section{REFERENCES}

Arkes, H. R., Faust, D., Guilmette, T. J., \& Hart, K. (1988). Eliminating the hindsight bias. Journal of Applied Psychology, 73, 305-307.

Arkes, H. R., Wortmann, R. L., Saville, P. D., \& Harkness, A. R. (1981). Hindsight bias among physicians weighing the likelihood of diagnoses. Journal of Applied Psychology, 66, 252-254.

Bukszar, E., \& ConNolly, T. (1988). Hindsight bias and strategic choice: Some problems in learning from experience. Academy of Management Journal, 31, 628-641.

Campbell, J. D., \& Tesser, A. (1983). Motivational interpretations of hindsight bias: An individual difference analysis. Journal of Personality, 51, 605-620.

CarLI, L. L., \& LeONARD, J. B. (1989). The effect of hindsight on victim derogation. Journal of Social \& Clinical Psychology, 8, 331-343.

CAsPer, J. D., Benedict, K., \& Kelly, J. R. (1988). Cognitions, attitudes and decision-making in search and seizure cases. Journal of Applied Social Psychology, 18, 93-113.

Davies, M. F. (1987). Reduction of hindsight bias by restoration of foresight perspective: Effectiveness of foresight-encoding and hindsight-retrieval strategies. Organizational Behavior \& Human Decision Processes, 40, 50-68.

Detmer, D. E., Fryback, D. G., \& Gassner, K. (1978). Heuristics and biases in medical decision-making. Journal of Medical Education, 53, 682-683.

EsTES, W. K. (1959). Component and pattern models with Markovian interpretations. In R. R. Bush \& W. K. Estes (Eds.), Studies in mathematical learning theory (pp. 9-52). Stanford, CA: Stanford University Press.

FischноF, B. (1975). Hindsight is not equal to foresight: The effect of outcome knowledge on judgment under uncertainty. Journal of Experimental Psychology: Human Perception \& Performance, 1, 288-299.

FischноF, B. (1977). Perceived informativeness of facts. Journal of Experimental Psychology: Human Perception \& Performance, 3, 349-358.

FischноF, B. (1982). Debiasing. In D. Kahneman, P. Slovic, \& A. Tversky (Eds.), Judgment under uncertainty: Heuristics and biases (pp. 422-444). New York: Cambridge University Press.

FischHoff, B., \& BEYTH, R. (1975). "I knew it would happen": Remembered probabilities of once-future things. Organizational Behavior \& Human Performance, 13, 1-16.

GoGGIN, W. C., RANGE, L. M. (1985). The disadvantages of hindsight in the perception of suicide. Journal of Social \& Clinical Psychology, 3, 232-237.
Gortein, B., Rotenberg, M. (1977). Protestantism and retrospective labeling: A cross-cultural study in person perception. Human Relations, 30, 487-497.

Hasher, L., AtTIG, M. S., \& Alba, J. W. (1981). I knew it all along: Or, did I? Journal of Verbal Learning \& Verbal Behavior, 20, 86-96.

Hawkins, S. A., \& Hastie, R. (1990). Hindsight: Biased judgments of past events after the outcomes are known. Psychological Bulletin, 107, 311-327.

Janoff-Bulman, R., Timko, C., \& Carli, L. (1985). Cognitive biases in blaming the victim. Journal of Experimental Social Psychology, 21, 161-177.

LEARY, M. R. (1981). The distorted nature of hindsight. Journal of Social Psychology, 115, 25-29.

LEARY, M. R. (1982). Hindsight distortion and the 1980 presidential election. Personality \& Social Psychology Bulletin, 8, 257-263.

LUCE, R. D., \& SUPPES, P. (1965). Preference, utility and subjective probability. In R. D. Luce, R. R. Bush, \& E. Galanter (Eds.), Handbook of mathematical psychology (Vol. 3, pp. 249-410). New York: Wiley.

MAzURSKY, D., OFIR, C. (1990). I could never have expected it to happen: The reversal of the hindsight bias. Organizational Behavior \& Human Decision Processes, 46, 20-33.

Pennington, D. C. (1981). The British firemen's strike of 1977/78: An investigation of judgements in foresight and hindsight. British Journal of Social Psychology, 20, 89-96.

PowelL, J. L. (1988). A test of the knew-it-all-along effect in the 1984 presidential and statewide elections. Journal of Applied Social Psychology, 18, 760-777.

SLOVIC, P., \& FisCHHOFF, B. (1977). On the psychology of experimental surprises. Journal of Experimental Psychology: Human Perception \& Performance, 3, 544-551.

Sue, S., Smith, R. E., \& CaldWell, C. (1973). Effects of inadmissible evidence on the decisions of simulated jurors: A moral dilemma. Journal of Applied Social Psychology, 3, 345-353.

Synodinos, N. E. (1986). Hindsight distortion: "I knew-it-all along and I was sure about it." Journal of Applied Social Psychology, 16, 107-117.

Verplanken, B., \& Pieters, R. G. (1988). Individual differences in reverse hindsight bias: I never thought something like Chernobyl would happen. Did I? Journal of Behavioral Decision Making, 1, 131-147.

VLEK, C. A. J. (1970). Multiple probability learning: Associating events with their probabilities of occurrence. Acta Psychologica, 33, 207-232.

WEXLER, D. B., \& SCHOPP, R. F. (1989). How and when to correct for juror hindsight bias in mental health malpractice litigation: Some preliminary observations. Behavioral Sciences \& the Law, 7, 485-504. WooD, G. (1978). The knew-it-all-along effect. Journal of Experimental Psychology: Human Perception \& Performance, 4, 345-353.

(Manuscript received April 11, 1991.) 